\title{
Viabilidade econômica da aplicação de lodo de esgoto em plantio de eucalipto
}

O lodo de esgoto (LE) aplicado em solos de florestas plantadas, com base no critério do nitrogênio, pode aumentar a produção de madeira sem causar danos ao ambiente florestal. Entretanto, ainda é necessário analisar a viabilidade econômica dessa prática que pode ser um fator limitante para a reciclagem deste resíduo. Assim, o objetivo do trabalho foi realizar a avaliação econômica do uso de $\operatorname{LE}(0 ; 7,7 ; 15,4$ e $23,1 \mathrm{Mg}$ ha-1) sem e com complementação de fertilizante mineral nitrogenado e fosfatado em comparação a adubação convencional de um povoamento de Eucalyptus grandis aos 7,9 anos após o seu plantio através do método de VPLA (Valor Presente Líquido Anualizado), TIR (Taxa Interna de Retorno) e IBC (Índice Benefício/Custo). Foram consideradas taxas de desconto de 6 e $12 \%$ a.a. e três cenários nos quais o produtor florestal assume por 100,50 e $0 \%$ dos custos de transporte do lodo. Verificou-se maior produção de madeira no tratamento com 15,4 Mg ha-1 de LE, o qual obteve 338 m3 ha-1. Porém, a adubação mineral convencional representou a opção com melhor viabilidade econômica em todas as situaç̃̃es analisadas, exceto para o cenário no qual o produtor florestal estaria isento do transporte do LE. Notou-se que a variação nas taxas de juros propostas proporcionou maiores acréscimos de VPLA que a alteração de cenários (redução do custo de transporte). Portanto, conclui-se que este produtor florestal apenas se motivaria em aplicar o lodo de esgoto em relação à prática já usual se o custo de transporte deste resíduo não fosse arcado por ele. É importante considerar também que o fator de risco associado ao mercado de LE para aplicação agrícola, o qual não é estruturado e coordenado, pode interferir na tomada de decisão deste produtor.

\section{Economic feasibility of the application of sewage sludge in eucalyptus plantation}

\begin{abstract}
Sewage sludge (LE) applied to planted forests soils, based on the nitrogen criterion, can increase wood production without damaging the forest environment. However, it is still necessary to analyze the economic viability of this practice, which may be a limiting factor for the recycling of this residue. The objective of this work was to evaluate the use of LE $(0,7.7,15.4$ and $23.1 \mathrm{Mg}$ ha-1) without and complementation of nitrogen and phosphatic fertilizer compared to conventional fertilization of Eucalyptus grandis plantation at 7.9 years after planting by means of the Annual Net Present Value (VPLA), Internal Rate of Return (TIR) and Benefit/Cost Ratio (IBC). Discount rates of 6 and $12 \%$ per year and three scenarios were considered in which the forest producer assumes 100,50 and $0 \%$ of the costs of transporting the sludge. It was verified a higher wood production in the treatment with $15.4 \mathrm{Mg}$ ha- 1 of LE, which obtained $338 \mathrm{~m} 3$ ha-1. Althought, conventional mineral fertilization represented the option with better economic viability in all situations analyzed, except for the scenario in which the forest producer would be exempt from LE transportation. It was noted that the variation in the proposed interest rates provided higher increases in VPLA than the change in scenarios (reduction of transport costs). Therefore, it is concluded that this forest producer would only be motivated to apply the sewage sludge in relation to the usual practice if the cost of transportation of this waste was not afforded by he. It is important to also consider that the risk factor associated with the LE market for agricultural application, which is not structured and coordinated, may interfere in this producer's decision-making.
\end{abstract}

Keywords: Biosolid; Eucalyptus Grandis; Wood Production; Forest Economy.

Topic: Planejamento, Gestão e Políticas Públicas Ambientais

Reviewed anonymously in the process of blind peer.
Received: 10/06/2018

Approved: 24/07/2018
Isabela Cristina Gomes Pires (iD)

Universidade de São Paulo, Brasil

http://lattes.cnpq.br/3393211586560026

http://orcid.org/0000-0002-9055-9435

icgpires@yahoo.com.br

Lúcia Pittol Firme de Moraes

Universidade de São Paulo, Brasil

http://lattes.cnpq.br/0399368004701790

lucia.pittolfirme@gmail.com

Gregori da Encarnação Ferrão (iD

Universidade Federal do Maranhão, Brasil

http://lattes.cnpq.br/4627304990166302

http://orcid.org/0000-0002-1740-6723

gregoriferrao@yahoo.com.br

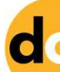

DOI: $10.6008 / C B P C 2179-6858.2018 .005 .0026$

\author{
Luiz Carlos de Faria (iD \\ Universidade Federal de São Carlos, Brasil \\ http://lattes.cnpq.br/2656343277991754 \\ http://orcid.org/0000-0003-1157-3528 \\ Icfaria@ufscar.br \\ Cássio Hamilton Abreu Júnior (D) \\ Universidade de São Paulo, Brasil \\ http://lattes.cnpq.br/3054341790713070 \\ http://orcid.org/0000-0002-5955-4652 \\ cahabreu@cena.usp.br
}

\section{Referencing this:}

PIRES, I. C. G.; MORAES, L. P. F.; FERRÃO, G. E.; FARIA, L. C.; ABREU JÚNIOR, C. H.. Viabilidade econômica da aplicação de lodo de esgoto em plantio de eucalipto. Revista Ibero Americana de Ciências Ambientais, v.9, n.5, p.294-307, 2018. DOI:

http://doi.org/10.6008/CBPC2179-6858.2018.005.0026 


\section{INTRODUÇÃO}

A disposição ambientalmente adequada do lodo de esgoto (LE), resíduo gerado nas estações de tratamento de esgoto, é um dos desafios da gestão de resíduos sólidos no Brasil, pois sua destinação final para corpos hídricos ou lixões é proibida (BRASIL, 1998), e até mesmo para aterro sanitário, uma vez que este resíduo pode ser reciclado, assim não se classifica como rejeito o qual possui a destinação ambientalmente adequada para aterro (BRASIL 2010). Estima-se que são produzidos de 150 a 220 mil toneladas de lodo por ano no Brasil (PEDROZA et al, 2010). Paralelamente, prevê-se a necessidade eminente da expansão de 12,4\% do tratamento de esgoto no país até 2030, o que, consequentemente, acarretará na elevação da geração do lodo de esgoto (BRASIL, 2013).

A reciclagem do lodo de esgoto em solos agrícolas, como sua aplicação em áreas florestais após o devido tratamento (CONAMA, 2006), é uma das alternativas aceitáveis nos âmbitos agronômico, ambiental e legal. Este resíduo possui matéria orgânica, macronutrientes (nitrogênio e fósforo) e micronutrientes (zinco) que potencializa o seu uso agrícola, uma vez que também pode funcionar como condicionador das propriedades físicas, químicas e biológicas do solo, além do fornecimento desses nutrientes (ABREU JUNIOR et al., 2005; FERNANDES et al., 2005; SINGH et al., 2007; JUNIO et al., 2013)

Porém, as agências regulamentadoras desta prática têm vetado as solicitações de aplicação de LE em solo agrícola paulista com o amparo da Resolução CONAMA n 375 de 2006, a qual proíbe o uso do lodo de esgoto de classe B, único tipo de lodo produzido no Brasil (ABREU JUNIOR et al., 2008). Ao mesmo tempo, diversos estudos demonstram que o uso deste tipo de lodo em solo de floresta plantada, desde que tomado os devidos cuidados, não causaria prejuízos ao ambiente florestal (GUEDES et al., 2006; LIRA; GUEDES; SCHALCH, 2008; FIRME, 2009; GARCIA et al., 2010, ROCHA et al., 2013; FERRAZ et al., 2014), sendo uma solução aconselhável onde há terras disponíveis (EANG, 2013).

Assim como é essencial avaliar o aspecto ambiental e silvicultural no uso agrícola de um resíduo, deve-se também analisar a sua viabilidade econômica para que a decisão não incorra em prejuízos ao produtor (PIRES et al., 2008), ou ainda, que políticas adotadas não sejam fadadas ao insucesso. Tanto que Faria (2007), ao estudar a viabilidade econômica da aplicação de lodo de esgoto em eucalipto antes da Política Nacional de Resíduos Sólidos, verificou que o produtor florestal não se sentiria atraído em aplicar o lodo de esgoto em sua área, uma vez que o retorno líquido (VPLA) do uso do fertilizante mineral é maior, sendo que foi considerado que este produtor arcaria com os custos de transporte e aplicação deste resíduo bem como elaboração de projeto técnico e os devidos monitoramentos conforme à norma (CONAMA, 2006).

Entretanto, o cenário legal em relação à destinação dos resíduos sólidos no Brasil torna-se mais incisivo quanto à responsabilidade do gerador com a Política Nacional de Resíduos Sólidos (BRASIL, 2010), desse modo, a ETE (Estação de Tratamento de Esgoto), geradora do resíduo, é, nitidamente, responsável pela destinação ambientalmente adequada do lodo de esgoto, devendo assim arcar com os custos referentes a este processo. 
Neste sentido, avaliou-se a viabilidade econômica da aplicação de lodo de esgoto complementado sem e com fertilizantes minerais nitrogenado e fosfatado em plantio de Eucalyptus grandis após 7,9 anos do plantio no município de Angatuba/SP, considerando que o produtor florestal se responsabilize por 100, 50 e $0 \%$ dos custos relacionados ao transporte do lodo de esgoto a taxa de descontos de 6 e $12 \%$ a.a..

\section{MATERIAIS E MÉTODOS}

\section{Descrição da área experimental}

O experimento foi instalado na fazenda Entre Rios, da Suzano Bahia Sul Papel e Celulose S.A., localizada no município de Angatuba ( $22^{\circ} 59^{\prime}$ de latitude sul e $48^{\circ} 41^{\prime}$ de longitude oeste), SP. $O$ clima deste município, segundo classificação de Köppen, é do tipo mesotérmico úmido, com precipitação média anual de $1350 \mathrm{~mm}$, temperatura média anual de $19,4^{\circ} \mathrm{C}$ e umidade relativa de $83,3 \%$, podendo ocorrer geadas leves nos meses de inverno.

O solo mais representativo da área experimental é um Latossolo Vermelho distrófico, sendo o solo desta área caracterizado como homogêneo quanto às suas propriedades físicas ( $12 \%$ de argila, $4 \%$ de silte e $84 \%$ de areia) e químicas (Tabela 1 ) da camada de $0-40 \mathrm{~cm}$ de profundidade.

Tabela 1: Características químicas do solo da área experimental, antes da instalação do experimento.

\begin{tabular}{|l|l|l|l|l|l|l|l|l|l|l|l|l|l|}
\hline Prof. & $\mathrm{pH}$ & $\mathrm{MO}^{(1)}$ & $\mathrm{N}$ & $\begin{array}{l}\mathrm{S}- \\
\mathrm{SO}_{4}^{2-}\end{array}$ & $\mathrm{P}$ & $\mathrm{K}$ & $\mathrm{Ca}$ & $\mathrm{Mg}$ & $\mathrm{H}+\mathrm{Al}^{(2)}$ & $\mathrm{SB}^{(3)}$ & $\mathrm{CTC}^{(4)}$ & $\mathrm{V}^{(5)}$ \\
\hline $\mathrm{Cm}$ & $\mathrm{CaCl}_{2}$ & $\mathrm{~g} \mathrm{dm}^{3}$ & $\begin{array}{l}\mathrm{g} \mathrm{kg} \\
1\end{array}$ & $\begin{array}{l}\mathrm{Mg} \mathrm{kg}^{-} \\
1\end{array}$ & $\begin{array}{l}\mathrm{mg} \\
\mathrm{dm}^{3}\end{array}$ & $\begin{array}{l}----------------\mathrm{mmol}_{\mathrm{c}} \mathrm{dm}^{3} \text {------ } \\
\text {------- }\end{array}$ & \multicolumn{5}{|c|}{} \\
\hline $0-20$ & $3,6^{(6)}$ & 20,2 & 0,43 & 1,2 & 6,5 & 0,25 & 1,25 & 1,00 & 40,0 & 2,5 & 42,5 & 5,7 \\
\hline $\begin{array}{l}20- \\
40\end{array}$ & 3,8 & 15,5 & 0,34 & 1,0 & 5,5 & 0,20 & 1,00 & 1,00 & 30,2 & 2,2 & 32,4 & 6,7 \\
\hline
\end{tabular}

(1) MO - Matéria orgânica; (2) H+Al - Acidez; (3) SB - Soma de bases; (4) CTC - Capacidade de troca de cátions; (5) V - Saturação por base; ${ }^{(6)}$ Resultados médios de 4 amostras analisadas.

\section{Caracterização do lodo de esgoto}

O LE usado no experimento foi gerado na Estação de Tratamento de Esgotos de Jundiaí, SP, em sistema de lagoas aeradas de mistura completa, seguida de lagoas de decantação, sendo o desaguamento feito com floculação à base de polímero catiônico, seguido de centrifugação e secagem em pátio revestido, com revolvimento mecânico. A característica deste resíduo (Tabela 2) está em conformidade com as concentrações máximas de substâncias inorgânicas permitidas para o seu uso em solo agrícola (CONAMA, 2006).

Tabela 1: Características químicas e físicas do lodo de esgoto utilizado no experimento e concentrações máximas de elementos inorgânicos permitidas pela Resolução CONAMA $n^{\circ} 375$ (CONAMA, 2006) para o uso agrícola do lodo de esgoto.

\begin{tabular}{|l|l|l|}
\hline Propriedade & & Concentrações Máximas Permitidas \\
\hline $\mathrm{pH}$ (em água) & $6,2^{(1)}$ & - \\
\hline Umidade (\%) & 79 & - \\
\hline Sólidos voláteis $(\%)$ & 65 & - \\
\hline Carbono orgânico $\left(\mathrm{g} \mathrm{kg}^{-1}\right)$ & 340 & - \\
\hline Nitrogênio total $\left(\mathrm{g} \mathrm{kg}^{-1}\right)$ & 33 & - \\
\hline $\mathrm{N}$ amoniacal $\left(\mathrm{g} \mathrm{kg}^{-1}\right)$ & 3,6 & - \\
\hline $\mathrm{N}$ nitrato-nitrito $\left(\mathrm{g} \mathrm{kg}^{-1}\right)$ & 0,018 & - \\
\hline
\end{tabular}




\begin{tabular}{|c|c|c|}
\hline Fósforo $\left(\mathrm{g} \mathrm{kg}^{-1}\right)$ & 8,1 & - \\
\hline Potássio (g kg-1) & 1 & - \\
\hline Cálcio $\left(\mathrm{g} \mathrm{kg}^{-1}\right)$ & 8,1 & - \\
\hline Enxofre $\left(\mathrm{g} \mathrm{kg}^{-1}\right)$ & 16,4 & - \\
\hline Sódio $\left(\mathrm{mg} \mathrm{kg}^{-1}\right)$ & 997 & - \\
\hline Magnésio $\left(\mathrm{g} \mathrm{kg}^{-1}\right)$ & 1,6 & - \\
\hline Ferro $\left(\mathrm{mg} \mathrm{kg}^{-1}\right)$ & 16062 & - \\
\hline Manganês (mg kg-1) & 483 & - \\
\hline Cobre $\left(\mathrm{mg} \mathrm{kg}^{-1}\right)$ & 881 & 1500 \\
\hline Molibdênio (mg kg-1) & $\mathrm{ND}^{(2)}$ & 50 \\
\hline Zinco $\left(\mathrm{mg} \mathrm{kg}^{-1}\right)$ & 989 & 2800 \\
\hline Arsênio (mg kg-1) & ND & 41 \\
\hline Cádmio (mg kg-1) & 11 & 39 \\
\hline Chumbo (mg kg-1) & 85 & 300 \\
\hline Cromo $\left(\mathrm{mg} \mathrm{kg}^{-1}\right)$ & 111 & 1000 \\
\hline Mercúrio $\left(\mathrm{mg} \mathrm{kg}^{-1}\right)$ & ND & 17 \\
\hline Níquel $\left(\mathrm{mg} \mathrm{kg}^{-1}\right)$ & 26 & 420 \\
\hline Selênio $\left(\mathrm{mg} \mathrm{kg}^{-1}\right)$ & ND & 100 \\
\hline Bário $\left(\mathrm{mg} \mathrm{kg}^{-1}\right)$ & 273 & 1300 \\
\hline
\end{tabular}

\section{Delineamento experimental}

Inicialmente, aplicou-se o calcário na área total $(1,8$ ton ha-1) com o objetivo de se obter uma porcentagem de saturação por bases de $45 \%$ na camada de $0-20 \mathrm{~cm}$ de profundidade. 0 potássio, sendo um nutriente escasso no lodo de esgoto (Tabela 2), foi aplicado em todas as parcelas experimentais (175 $\mathrm{kg} \mathrm{ha}^{-1}$ de $\mathrm{K}_{2} \mathrm{O}$ ) na forma de $\mathrm{KCl}$ e parcelado em quatro vezes.

Os tratamentos foram constituídos por quatro doses de LE de $0 ; 7,7 ; 15,4$ e $23,1 \mathrm{Mg} \mathrm{ha}^{-1}$ a base seca $(0,50,100$ e $150 \%$ do recomendado pelo critério de $N)$, quatro doses de nitrogênio de 0; 46,9; 95,1 e $142 \mathrm{~kg}$ ha $^{-1}$ e quatro doses de fósforo de $0 ; 28 ; 55,9$ e $84 \mathrm{~kg} \mathrm{ha}^{-1}$, correspondendo a 0, 33, 67 e $100 \%$ do recomendado para a fertilização mineral nitrogenada e fosfatada pela empresa responsável pela área. Desse modo, o experimento foi delineado em esquema fatorial $4 \times 4 \times 4$, assim definiu-se 64 tratamentos os quais foram delineados em blocos ao acaso, com duas repetições, totalizando 128 parcelas, sendo o espaçamento de $3 \times 2 \mathrm{~m}$ entre as plantas.

O LE foi distribuído superficialmente no solo com auxílio de uma adubadeira. A aplicação do fertilizante nitrogenado (ureia) e fosfatado (superfosfato triplo) foi realizada manualmente em meia coroa ao redor da muda de eucalipto (clone grandis puro SP0619) a qual foi plantada a $20 \mathrm{~cm}$ da faixa de aplicação do lodo e sob condições de cultivo mínimo.

\section{Estimativa da produção de madeira}

Aos 7,9 anos do plantio, abateram-se três árvores representativas de 28 parcelas do experimento, estes indivíduos foram selecionados previamente com base na distribuição de classes de frequência de circunferência à altura do peito (CAP). Mensuraram-se as seguintes variáveis de cada eucalipto abatido: altura comercial (sem ponteiro limitando o diâmetro comercial em $5 \mathrm{~cm}$ ), circunferência na altura do peito (CAP) e área da extremidade menor e maior da tora. 
O volume comercial de madeira com casca $\left(\mathrm{m}^{3}\right)$ em cada parcela analisada foi calculado considerando o volume comercial das árvores representativas, obtido pelo método Smalian conforme eq. 1 (VEIGA, 1984) e o número de árvores na área útil da parcela. A estimativa do volume comercial de madeira com casca para todas as parcelas do experimento foi realizada pelo DAP dos indivíduos não abatidos e por meio do fator de correlação $\left(R^{2}=0,98\right.$ e $\left.p<0,001\right)$ entre a área seccional de diâmetro à altura do peito (DAP) das árvores abatidas e o seu respectivo volume de madeira. E para a estimativa da produção de madeira com casca por hectare $\left(\mathrm{m}^{3} \mathrm{ha}^{-1}\right)$, utilizou-se o volume comercial de madeira com casca e o tamanho da área útil da parcela. Posteriormente, a determinação do incremento médio anual (IMA) da produção de madeira com casca ( $\mathrm{m}^{3}$ $\mathrm{ha}^{-1} \mathrm{ano}^{-1}$ ) foi baseada no volume de madeira por hectare de cada parcela e na rotação de 7,9 anos.

$$
V=\left(\left(A_{1}+A_{2}\right) / 2\right) * C
$$

Em que: $V=$ volume em metro cúbico $\left(m^{3}\right) ; A_{1}=a$ área da extremidade menor da tora; $A_{2}=a$ área da extremidade maior da tora e $\mathrm{C}=\mathrm{o}$ comprimento do torete em metro $(\mathrm{m})$.

\section{Avaliação econômica}

\section{Receitas}

O levantamento das receitas foi baseado no volume de madeira em pé de eucalipto por hectare obtidos nos diferentes tratamentos e no preço de venda da madeira em pé para o estado de São Paulo de 49,03 R\$ $\mathrm{m}^{3}$ (CEPEA, 2013).

\section{Custos}

O levantamento dos custos foi baseado no conceito de custo operacional efetivo (COE), são aqueles referentes a despesas diretas de custeio incorridas pelo produtor florestal na condução de sua atividade rural (MATSUNGA et al., 1976; NORONHA, 1981). Para o presente trabalho foram consideradas como itens de custo: i) transporte, aquisição e distribuição dos fertilizantes minerais; ii) transporte e distribuição do lodo de esgoto, considerado sem custo de aquisição, uma vez que não possui mercado próprio. 0 custo do adubo nitrogenado na forma de ureia e do adubo fosfatado na forma de superfosfato triplo foi de 1224,93 e de 1230,43 R\$ Mg-1 , respectivamente, e são referentes à média de valores do ano de 2013 para o estado de São Paulo (IEA, 2014).

O custo de transporte do lodo foi de 75,00 $\mathrm{R} \$ \mathrm{Mg}^{-1}$, sendo este transporte baseado no valor de mercado utilizado pela transportadora que presta serviços a ETE de Jundiaí (informação verbal) ${ }^{1}$. O custo médio de transporte do fertilizante mineral é de $55 \mathrm{R} \mathrm{Mg}^{-1}$ para uma distância de, aproximadamente, 270 Km que representa a distância do Porto de Cubatão, porto mais próximo da área de aplicação, até o município de Angatuba, onde localiza-se a área experimental do presente trabalho (SIFRECA, 2014).

Para o custo de distribuição do lodo de esgoto na área foi considerado o custo hora-máquina e horahomem. Para o primeiro custo foram utilizadas as equações 2 e 3 (OSAKI, 2012) e para o segundo, a

\footnotetext{
1 Informação repassada pelo Dr. Fernando Carvalho Oliveira da empresa Biossolo Agricultura e Ambiente Ltda. em 2014
} 
remuneração mensal do profissional tratorista (IEA, 2014). Portanto, o custo por hectare de distribuição do lodo na área florestal foi de $\mathrm{R} \$ 95,10$ para o tratamento de 7,7 e de 15,4 $\mathrm{Mg} \mathrm{ha}^{-1}$ de lodo e de $\mathrm{R} \$ 114,12$ para o tratamento de 23,1 Mg ha-1 ${ }^{-1}$ Le LE. Como a distribuição dos fertilizantes minerais foi manual, considerou-se apenas o custo hora-homem o qual se baseou no valor da mão-de-obra da categoria de diarista a seco (IEA, 2014)

Custo hora-máquina trator $=(0,12 * C v * D)+((V n-V n * 0,2) / V u) * t m$

Em que: $\mathrm{CV}$ = potência do trator em unidade de cavalo vapor, $\mathrm{D}=$ preço em reais do óleo diesel por litro, $\mathrm{Vn}=$ valor do trator novo, $\mathrm{Vu}=$ vida útil do trator, $\mathrm{tm}=$ taxa de manutenção preventiva com o trator.

Custo hora-máquina distribuidor de calcário $=\left(\left(V_{n}-V_{n} * 0,2\right) / V u\right) * t m$

Em que: $\mathrm{Vn}=$ valor do distribuidor de calcário novo, $\mathrm{Vu}=$ vida útil do distribuidor de calcário, $\mathrm{tm}=$ taxa de manutenção preventiva com o distribuidor de calcário.

\section{Critério de avaliação econômica}

A avaliação econômica foi realizada pelo fluxo de caixa das receitas e os custos em um determinado tempo utilizando-se o critério do Valor Presente Líquido Anualizado (VPLA), obtido conforme a eq. 4 (REZENDE et al., 2001). Para a interpretação do VPLA, considerou-se como tratamento mais viável economicamente aquele com maior valor de VPLA.

$$
\left(\begin{array}{lll}
n & \mathrm{VPLA} & = \\
t=0 & \sum_{t=0} & \mathrm{R}_{t} \\
(1+i)^{t}
\end{array}\right)-\left(\frac{\Sigma \mathrm{C}_{t}}{(1+i)^{t}}\right) \quad i(1+i)^{t}
$$

Em que: $R_{t}=$ Receita no período $t ; C_{t}=$ Custo no período $t ; i=$ taxa de descontos.

Analisou-se também a Taxa Interna de Retorno (TIR) e o Índice Benefício-Custo (IBC) para os diferentes tratamentos de acordo com a eq. 5 e 6 respectivamente (REZENDE et al., 2001). Os cálculos foram realizados pelas funções financeiras do Excel (SOUZA et al., 2004).

$$
\begin{aligned}
& \sum R_{t}(1+T I R)^{-t}=\sum C_{t}(1+T I R)^{-t} \\
& I B C=\text { Valor presente do fluxo de benefícios } \\
& \text { Valor presente do fluxo de investimento }
\end{aligned}
$$

\section{Cenários}

Considerando que a ETE é responsável por operacionalizar integralmente o plano de gerenciamento do LE com destinação ambientalmente adequada dos resíduos conforme a Política Nacional de Resíduos Sólidos (BRASIL, 2010), a análise do VPLA foi baseada na simulação de cenários nos quais o produtor florestal arcaria com 100, 50 e 0 \% do custo de transporte do LE na produção florestal.

A taxa de descontos constitui um elemento crítico na avaliação de alternativas, principalmente, em empreendimentos florestais, que são caracterizados pelo longo prazo dos investimentos (REZENDE et al., 2001). Para o presente trabalho adotou-se as taxas de desconto de 6 e $12 \%$ a.a. para a análise de 
sensibilidade deste estudo, pois abrange os extremos de taxas de desconto relatadas na literatura para projetos florestais (LIMA JÚNIOR et al., 1997). Assim, foram calculados os indicadores econômicos com duas taxas de desconto considerando três cenários para o custo de transporte do lodo pago pelo produtor florestal conforme Tabela 3.

Tabela 3: Descrição dos cenários e taxas de desconto analisados.

\begin{tabular}{|l|l|l|l|}
\hline $\begin{array}{l}\text { Taxa de descontos } \\
\text { (\% a.a.) }\end{array}$ & Proporção do custo de transporte do lodo pago pelo produtor florestal & \multicolumn{2}{|l|}{} \\
\cline { 2 - 4 } & Cenário 1 & Cenário 2 & Cenário 3 \\
\hline 12 & $100 \%$ & $50 \%$ & $0 \%$ \\
\hline
\end{tabular}

\section{Análise estatística}

Os dados foram compilados em planilhas do Microsoft ${ }^{\circledR}$ Office $^{\mathrm{TM}}$ Excel e a sua análise estatística, após constatar a normalidade dos dados pelo teste de Shapiro-Wilk $(p<0,05)$, foi realizada através da comparação de médias do volume de madeira pela análise de variância (ANOVA) usando o procedimento PROC GLM e o teste de Tukey $(p<0,06)$ pelo Statistical Analysis System - SAS v.9.3 (SAS Inc, Cary, EUA).

\section{RESULTADOS E DISCUSSÃO}

\section{Produção comercial de madeira com casca}

A produção comercial de volume de madeira com casca de eucalipto variou de 254 a $338 \mathrm{~m}^{3}$ ha $^{-1}$ (Tabela 4), sendo que a maior e menor produção foi obtida no tratamento com dose de $15,4 \mathrm{Mg}$ ha $^{-1}$ de lodo e no controle respectivamente. Verificou-se aumento de $27,31,32$ e $33 \%$ em relação ao controle para os tratamentos de 23,1; 7,7; adubação convencional e 15,4 $\mathrm{Mg} \mathrm{ha}^{-1}$ de LE respectivamente. A fertilização mineral convencional obteve volume de madeira semelhante aos tratamentos que utilizaram a dose de 7,7 e 23,1 Mg ha ${ }^{-1}$ de lodo pela análise estatística.

Tabela 4: Produção e produtividade de madeira de eucalipto com casca aos 7,9 anos de idade.

\begin{tabular}{|c|c|c|c|c|}
\hline \multirow[t]{2}{*}{ Controle } & \multirow[t]{2}{*}{ Adubação convencional } & \multicolumn{2}{|l|}{ Doses de lodo (Mg ha-1) } & \\
\hline & & 7,7 & 15,4 & 23,1 \\
\hline \multicolumn{5}{|c|}{----- m³ ha-1---- } \\
\hline $254 \mathrm{~B}$ & $335 \mathrm{AB}$ & $333 A B$ & $338 \mathrm{~A}$ & $322 \mathrm{AB}$ \\
\hline \multicolumn{5}{|c|}{---- $\mathrm{m}^{3} \mathrm{ha}^{-1} \mathrm{ano}^{-1}$} \\
\hline 30,3 & 42,3 & 42,2 & 42,8 & 40,8 \\
\hline
\end{tabular}

${ }^{*}$ Médias seguidas de mesma letra na linha não diferem estatisticamente entre si pelo teste Tukey ao nível de $6 \%$ de probabilidade.

Na literatura, é recorrente o uso de dose de LE equivalente à adubação mineral convencional em relação à produção independente da cultura (MACEDO et al., 2012), assim como constatações de doses de LE com produtividade superior ao obtido em adubação mineral convencional (TRANNIN et al., 2005; LEMAINSKI et al., 2006A; LEMAINSKI et al., 2006B; QUINTANA et al., 2009; LOBO et al., 2013). No ambiente florestal, os resultados são similares (VAZ et al., 2002; ROCHA et al., 2004; GUEDES et al., 2006; GARCIA et al., 2010; ROCHA et al., 2013). 
De acordo com Lira, Guedes e Schalch (2008), em plantio de eucalipto aos 5 anos de idade, verificouse que o uso de $10 \mathrm{Mg} \mathrm{ha}^{-1}$ de LE apresentou semelhante desenvolvimento (produção de biomassa) quando comparado aos que receberam adubação convencional. Conforme Faria (2007), na aplicação de LE em plantio de eucalipto, o melhor desempenho, no quesito produção de madeira, foi notado no tratamento com $10 \mathrm{Mg}$ ha-1 de LE complementado com potássio e fósforo $\left(371 \mathrm{~m}^{3} \mathrm{ha}^{-1}\right)$ aos 8 anos e 3 meses de idade destes indivíduos, sendo esta produção semelhante estatisticamente à adubação mineral convencional (362 $\mathrm{m}^{3}$ ha$\left.{ }^{1}\right)$ e ao tratamento de $15 \mathrm{Mg}$ ha ${ }^{-1}$ de de LE complementado com potássio ( $345 \mathrm{~m}^{3}$ ha-1 ), obtendo assim um aumento de 53, 49 e $42 \%$ em relação à testemunha $\left(242 \mathrm{~m}^{3} \mathrm{ha}^{-1}\right)$ respectivamente.

Desse modo, tanto no presente trabalho como no relatado por Faria (2007), observa-se doses de LE com resultados superiores à adubação mineral convencional por uma análise estatística descritiva, apesar dos tratamentos possuírem uma maior diferença em relação ao controle em Faria (2007), que pode estar relacionado ao fato do solo do controle deste experimento ter sido beneficiado pelo calcário. Porém, não há o suporte da interpretação da estatística paramétrica de comparação de médias em Faria (2007).

Quanto ao incremento médio anual (IMA), este variou entre 30 e $43 \mathrm{~m}^{3} \mathrm{ha}^{-1}$ ano-1 (Tabela 4). A dose de 15,4 Mg ha-1 de lodo de esgoto $\left(42,8 \mathrm{~m}^{3} \mathrm{ha}^{-1} \mathrm{ano}^{-1}\right)$ e o controle $\left(30,3 \mathrm{~m}^{3} \mathrm{ha}^{-1} \mathrm{ano}^{-1}\right)$, obtiveram o maior e menor IMA respectivamente, refletindo os resultados da produção. Os valores obtidos de IMA estão abaixo do esperado conforme recomendação técnica da empresa responsável pela área em estudo ( $50 \mathrm{~m}^{3} \mathrm{ha}^{-1}$ ano $^{-1}$ ), porém estão próximos da média brasileira de $40,7 \mathrm{~m}^{3} \mathrm{ha}^{-1}$ ano ${ }^{-1}$ (ABRAF, 2013).

\section{Viabilidade econômica}

$\mathrm{Na}$ análise deste trabalho, o custo para a aplicação de LE contempla os valores relacionados ao transporte e à sua distribuição no solo. Constatou-se que o maior custo é referente ao transporte, como já observado na literatura (HENRY; COLE, 1997; TRANNIN; SIQUEIRA; MOREIRA, 2005; FARIA, 2007). O custo de transporte do lodo foi de $577,50 \mathrm{R} \$ \mathrm{ha}^{-1}$ ( $86 \%$ do custo total), 1.155,00 R\$ ha-1 (92\% do custo total) e de

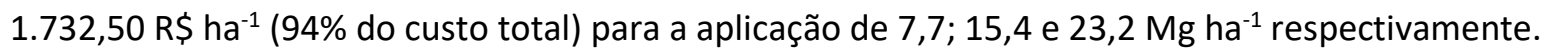

\section{Cenário 1}

No cenário 1, o VPLA variou de 1481 a $1830 \mathrm{R} \$ \mathrm{ha}^{-1}$ ano para taxas de $6 \%$ a.a. e de 1125 a $1484 \mathrm{R} \$$ ha ${ }^{-1}$ ano para taxas de 12 \% a.a., quanto ao TIR houve variação de 39 a 71 \% e ao IBC de 7 a 22 (Tabela 5). Independente da variável, a adubação mineral convencional obteve os melhores valores quanto a sua viabilidade econômica, diferente do verificado quando se considera somente o quesito produção (Tabela 5).

Desse modo, a opção mais atrativa para o produtor florestal é o uso de adubação convencional, o qual obteve os maiores valores de VPLA (1830 e 1484 R\$ ha-1 ano a taxa de 6 e $12 \%$ a.a. respectivamente), TIR (71\%) e IBC (22). Neste cenário, este produtor não se sentirá motivado em aplicar lodo de esgoto, manteria, assim, a utilização somente de fertilizantes minerais como já estabelecido.

Em relação à aplicação do LE, observou-se que a aplicação recomendada seria a de $7,7 \mathrm{Mg} \mathrm{ha}^{-1}$, uma vez que possui os valores mais altos (VPLA: 1763 e 1409 R\$ ha-1 ano a taxa de 6 e 12\% a.a. respectivamente; 
TIR: $58 \%$ e IBC: 16) quando comparado aos outros tratamentos com lodo. Assim, o que é sugerido apenas considerando o aspecto de produção, dose de 15,4 Mg ha-1 LE (Tabela 4), difere daquele que pondera as variáveis econômicas e financeiras, dose de $7,7 \mathrm{Mg} \mathrm{ha}^{-1} \mathrm{LE}$ (Tabela 5).

Tabela 5: Valor Presente Líquido Anualizado (VPLA), Taxa Interna de Retorno (TIR) e Índice Benefício Custo (IBC) médio para o Cenário 1.

\begin{tabular}{|c|c|c|c|c|c|c|}
\hline \multirow[t]{3}{*}{ Indicador econômico } & \multirow[t]{3}{*}{ Taxa de desconto (\% a.a.) } & \multirow[t]{3}{*}{ Controle } & \multirow[t]{3}{*}{ Adubação convencional } & \multirow[b]{2}{*}{ Dose de lodo $\left(\mathrm{Mg} \mathrm{ha}^{-1}\right)$} & & \\
\hline & & & & & & \\
\hline & & & & 7,7 & 15,4 & 23,1 \\
\hline \multirow[t]{2}{*}{$\operatorname{VPLA}\left(\mathrm{R} \$ \mathrm{ha}^{-1} \mathrm{ano}^{-1}\right)$} & 6 & 1481 & 1830 & 1763 & 1693 & 1500 \\
\hline & 12 & 1233 & 1484 & 1409 & 1318 & 1125 \\
\hline TIR (\%) & - & - & 71 & 58 & 47 & 39 \\
\hline IBC & - & - & 22 & 16 & 10 & 7 \\
\hline
\end{tabular}

Segundo Faria (2007), ao contrário de Trannin et al. (2005) e Lemainski et al. (2006a; 2006b) em estudos de viabilidade econômica de milho e soja, não houve tratamento com taxa de aplicação de $\mathrm{LE}$, complementada ou não, em eucalipto que possuísse VPLA equivalente ao obtido pela fertilização convencional (758 $\mathrm{R} \$ \mathrm{ha}^{-1}$ ano), considerando custos de transporte, distribuição do LE e requisitos legais exigidos pela resolução CONAMA (2006).

Verifica-se que mesmo o presente trabalho desconsiderando o fator elaboração de projeto técnico e monitoramento de lodo nas ETE's e de solos nas áreas de aplicação, a viabilidade econômica não é favorável para o uso de lodo de esgoto quando comparado à fertilização mineral convencional em eucalipto. Desse modo, o produtor florestal que já realiza a adubação convencional dificilmente se sentiria atraído em usar estes resíduos.

Então, no cenário que o produtor florestal arca com $100 \%$ dos custos de transporte deste resíduo, a sequência preferencial é: Considerando a taxa de $6 \%$ a.a.: fertilização mineral convencional $>7,7 \mathrm{Mg}$ ha ${ }^{-1} \mathrm{LE}$ $>15,4 \mathrm{Mg} \mathrm{ha}{ }^{-1} \mathrm{LE}>23,1 \mathrm{Mg} \mathrm{ha}^{-1} \mathrm{LE}>$ controle; Considerando a taxa de $12 \%$ a.a.: fertilização mineral convencional > 7,7 $\mathrm{Mg} \mathrm{ha}^{-1} \mathrm{LE}>15,4 \mathrm{Mg} \mathrm{ha}^{-1} \mathrm{LE}>$ controle > 23,1 $\mathrm{Mg} \mathrm{ha}^{-1} \mathrm{LE}$.

\section{Cenário 2}

No cenário 2, o VPLA variou de 1481 a $1830 \mathrm{R} \$ \mathrm{ha}^{-1}$ ano para taxas de $6 \%$ a.a. e de 1232 a $1484 \mathrm{R} \$$ ha $^{-1}$ ano para taxas de 12 \% a.a., quanto ao TIR houve variação de 51 a 71 \% e ao IBC de 11 a 22 (Tabela 6). Observou-se um aumento geral nos valores dos indicadores com aplicação do LE, uma vez que neste cenário considerou-se a redução dos custos de transporte de $L E$, impactando diretamente em um status mais atrativo para o uso do LE em plantio florestal.

Porém, assim como no cenário 1, a melhor opção para o produtor florestal é o uso de adubação convencional, o qual manteve os maiores valores de VPLA (1830 e $1484 \mathrm{R} \$ \mathrm{ha}^{-1}$ ano a taxa de 6 e $12 \%$ a.a. respectivamente), TIR (16\%) e IBC (22). Portanto, o produtor permaneceria com o comportamento de utilizar apenas fertilizantes minerais convencional no plantio de eucalipto.

Em relação à aplicação do LE, observou-se que a aplicação recomendada seria a de $7,7 \mathrm{Mg} \mathrm{ha}{ }^{-1}$, uma vez que possui os valores mais altos (VPLA: 1812 e $1466 \mathrm{R}$ ha-1 ano a taxa de 6 e $12 \%$ a.a. respectivamente; 
TIR: $68 \%$ e IBC: 22) quando comparado aos outros tratamentos com lodo. Desse modo, o que é sugerido apenas considerando o aspecto de produção, dose de 15,4 Mg ha-1 LE (Tabela 4), difere daquele que pondera as variáveis econômicas e financeiras, dose de 7,7 Mg ha-1 LE (Tabela 6). Então, da mesma forma que no cenário 1, neste cenário que o produtor florestal arca com $50 \%$ dos custos de transporte do lodo de esgoto, a sequência preferencial é: fertilização mineral convencional > 7,7 $\mathrm{Mg} \mathrm{ha}^{-1} \mathrm{LE}>15,4 \mathrm{Mg} \mathrm{ha}^{-1} \mathrm{LE}>23,1 \mathrm{Mg}$ ha ${ }^{1} \mathrm{LE}>$ controle.

Tabela 6: Valor Presente Líquido Anualizado (VPLA), Taxa Interna de Retorno (TIR) e Índice Benefício Custo (IBC) médio para o Cenário 2.

\begin{tabular}{|c|c|c|c|c|c|c|}
\hline \multirow[t]{2}{*}{$\begin{array}{l}\text { Indicador } \\
\text { econômico }\end{array}$} & \multirow[t]{2}{*}{$\begin{array}{l}\text { Taxa de desconto (\% } \\
\text { a.a.) }\end{array}$} & \multirow[t]{2}{*}{ Controle } & \multirow[t]{2}{*}{$\begin{array}{l}\text { Adubação } \\
\text { convencional }\end{array}$} & $\begin{array}{l}\text { Dose de lodo (Mg ha- } \\
\text { 1) }\end{array}$ & & \\
\hline & & & & 7,7 & 15,4 & 23,1 \\
\hline \multirow[t]{2}{*}{ VPLA (R\$ ha-1 ano $\left.{ }^{-1}\right)$} & 6 & 1481 & 1830 & 1812 & 1791 & 1647 \\
\hline & 12 & 1232 & 1484 & 1466 & 1432 & 1296 \\
\hline TIR (\%) & - & - & 71 & 68 & 59 & 51 \\
\hline IBC & - & - & 22 & 22 & 16 & 11 \\
\hline
\end{tabular}

\section{Cenário 3}

No cenário 3, o VPLA variou de 1481 a $1889 \mathrm{R} \$ \mathrm{ha}^{-1}$ ano para taxas de $6 \%$ a.a. e de 1232 a $1545 \mathrm{R} \$$ ha $^{-1}$ ano para taxas de 12 \% a.a., quanto ao TIR houve variação de 71 a 86 \% e ao IBC de 22 a 44 (Tabela 7). E notou-se uma elevação nos valores dos indicadores com aplicação do $L E$, de modo a superar os valores obtidos para adubação mineral convencional.

Tabela 7: Valor Presente Líquido Anualizado (VPLA), Taxa Interna de Retorno (TIR) e Índice Benefício Custo (IBC) médio para o Cenário 3.

\begin{tabular}{|c|c|c|c|c|c|c|}
\hline \multirow[t]{2}{*}{$\begin{array}{l}\text { Indicador } \\
\text { econômico }\end{array}$} & \multirow[t]{2}{*}{$\begin{array}{l}\text { Taxa de desconto (\% } \\
\text { a.a.) }\end{array}$} & \multirow[t]{2}{*}{ Controle } & \multirow[t]{2}{*}{$\begin{array}{l}\text { Adubação } \\
\text { convencional }\end{array}$} & $\begin{array}{l}\text { Dose de lodo (Mg ha- } \\
\text { 1) }\end{array}$ & & \\
\hline & & & & 7,7 & 15,4 & 23,1 \\
\hline \multirow[t]{2}{*}{ VPLA (R\$ ha-1 ano-1) } & 6 & 1481 & 1830 & 1861 & 1889 & 1775 \\
\hline & 12 & 1232 & 1484 & 1522 & 1545 & 1445 \\
\hline TIR (\%) & - & - & 71 & 85 & 86 & 78 \\
\hline IBC & - & - & 22 & 43 & 44 & 28 \\
\hline
\end{tabular}

Neste cenário, a melhor opção para este produtor de eucalipto seria a aplicação de LE na dose de 15,4 Mg ha-1 (VPLA: 1889 e 1545 R\$ ha-1 ano a taxa de 6 e 12\% a.a. respectivamente; TIR: 86\% e IBC: 44), sendo que estes valores de indicadores foram próximos para a dose de 7,7 Mg ha-1 de LE (VPLA: 1861 e 1522 $\mathrm{R} \$ \mathrm{ha}^{-1}$ ano a taxa de 6 e $12 \%$ a.a. respectivamente; TIR: $85 \%$ e IBC: 43 ).

Desse modo, ao contrário dos outros cenários, quando o produtor é isento dos custos de transporte, a aplicação de lodo de esgoto torna-se atraente quando comparado ao uso de fertilizante mineral. Assim, a melhor opção indicada pelo âmbito de produção (Tabela 4) é coerente com a perspectiva econômicofinanceira (Tabela 7) neste cenário, ou seja, a dose de 15,4 $\mathrm{Mg} \mathrm{ha}^{-1} \mathrm{LE}$.

Portanto, neste cenário que o produtor florestal arca com $0 \%$ dos custos de transporte do lodo de esgoto, a sequência preferencial é: $15,4 \mathrm{Mg} \mathrm{ha}^{-1} \mathrm{LE}>7,7 \mathrm{Mg} \mathrm{ha}^{-1} \mathrm{LE}>$ fertilização mineral $>23,1 \mathrm{Mg}$ ha ${ }^{-1} \mathrm{LE}>$ controle. 
É válido relatar que a análise neste cenário deve considerar o fator do mercado de LE não possuir uma cadeia coordenada o que implica em risco de operações, esta situação de risco pode levar o produtor, estudado neste trabalho, a desconsiderar o uso agrícola de lodo de esgoto apesar de sua viabilidade técnica e econômica, pois esta viabilidade é diretamente influenciada pela dinâmica de comercialização deste resíduo.

$\mathrm{Na}$ análise de VPLA para os diferentes cenários, nota-se que o produtor florestal se beneficia mais quando há a diminuição da taxa de descontos (variação de VPLA entre 330 e 375 R\$ ha-1 ano-1) que na redução dos custos relacionados à aplicação de lodo de esgoto (variação de VPLA entre 49 e $170 \mathrm{R} \$ \mathrm{ha}^{-1} \mathrm{ano}^{-1}$ ). Assim, na política de incentivo do seu uso florestal pode compensar mais o desenvolvimento de uma política monetária, diminuindo os valores das taxas de desconto que a argumentação sobre a Política Nacional de Resíduos Sólidos e seu quesito de responsabilidade do gerador, gerando assim maiores valores de VPLA ao produtor florestal.

Aqui é evidente, que o uso do LE na produção florestal só será possível com a desoneração do transporte para este produtor. Assim, iniciativas como observadas no Paraná são essenciais para o sucesso desta alternativa sustentável, sendo elas: i) lodo fornecido sem custo ao agricultor; ii) assistência agronômica arcada pela geradora do resíduo ou pelo Instituto Paranaense de Assistência Técnica e Extensão Rural (Emater). Assim, houve redução média nos custos de fertilizantes e corretivos de acidez do solo de $\mathrm{R} \$ 443,28$ ha $^{-1}$ para os agricultores (BITTENCOURT; AISSE; SERRAT, 2017), atraindo-os para realizar esta aplicação.

Mesmo com estas iniciativas, constatou-se que a ausência de infraestrutura aliada à complexidade da gestão influenciou para que apenas 22\% do total de 81 UGLs (Unidade de Gerenciamento de Lodo) paranaenses licenciadas destinassem o lodo para uso agrícola, sendo um dos motivos pautados pelas análises laboratoriais de lodo de esgoto demonstrar resultados inconsistentes, não permitindo a destinação deste material ao uso agrícola (BITTENCOURT et al., 2017).

Para se responder se "Afinal, queremos ou não viabilizar o uso agrícola do lodo produzido em estações de esgoto sanitário" (SAMPAIO, 2013), por uma perspectiva macro, pode-se dizer que para esta viabilização, é necessário que haja: i) revisão da Resolução CONAMA de 2006 (SAMPAIO, 2013); ii) desenvolvimento de gestão do processo de escoamento do lodo de esgoto, do momento de geração até sua destinação, preocupando-se com aspectos de formação de lotes em períodos próximos a demanda agrícola e profissionais capacitados para a gestão deste processo (BITTENCOURT et al., 2017); iii) coordenação entre os agentes envolvidos no processo, sendo eles: ETE, produtor, órgão ambiental competente e profissionais técnicos responsáveis pelo manejo agroflorestal.

E para responder diante do presente trabalho, pautado na perspectiva do produtor florestal, podese afirmar que só é possível atrair este produto se: Desonerá-lo dos custos relacionados à exigência da Resolução CONAMA (2006); Isentá-lo do custo do transporte; Inseri-lo como agente envolvido na cadeia de destinação ambientalmente adequada de $L E$, repercutindo positivamente em aspectos de planejamento e operacionalização em relação à frequência de abastecimento de LE bem como seu padrão de qualidade, além de outros feedbacks que fortaleçam o uso florestal deste resíduo; 
A estratégia de comercializar os seus produtos florestais com a chamada de serem ecologicamente corretos, contribuindo para a sustentabilidade ambiental, pode ser uma possibilidade de diferenciação na sua política de comercialização, podendo atrair mais consumidores e tornar-se mais competitiva (SOUZA FILHO, 2007). A partir daí, poderia se pensar em valor agregado ao lodo de esgoto como sugere Quintana, Bueno e Melo (2012).

Por fim, evidencia-se que a viabilidade econômica do LE em plantio florestal pode ser mais atraente ao pequeno produtor florestal, pois o uso de fertilizante mineral é menor quando comparado ao produtor deste estudo, influenciando nos custos, apesar de também interferir nos resultados de produção, assim impactando nos valores de receitas.

\section{CONCLUSÕES}

Quando o produtor florestal arca com 100 e $50 \%$ dos custos de transporte de lodo de esgoto, ele não se sente motivado em utilizá-lo como insumo da produção florestal independente da taxa de desconto, prefere manter o uso da adubação mineral convencional. Isento dos custos de transporte de lodo de esgoto, a utilização de 15,4 Mg ha-1 de LE pode atrair o produtor conforme os indicadores econômicos analisados, devido ao melhor retorno econômico. Porém, fatores relacionados à política de comercialização de LE, como uma cadeia descoordenada e legislação ambiental que onere o produtor, podem interferir negativamente no incentivo ao uso agrícola deste resíduo.

AGRADECIMENTOS: Agradecemos à FAPESP (processo 2004/15097-0) e ao CNPQ (485205/2012-2) pelo apoio financeiro, à empresa Suzano Papel e Celulose pela área experimental, bem como pela assistência operacional fornecida, à Companhia Saneamento de Jundiaí pelo fornecimento do lodo de esgoto, à CAPES pela bolsa de mestrado do primeiro autor e ao CNPq pela Bolsa de Produtividade de Pesquisa do quinto autor.

\section{REFERÊNCIAS}

ABRAF. Associação Brasileira de Produtores de Florestas Plantadas. Anuário estatístico 2013: ano base 2012. Brasília, 2013.

ABREU JUNIOR, C. H.; BOARETTO, A. E.; MURAOKA, T.; KIEHL, J. C.. Uso agrícola de resíduos orgânicos: propriedades químicas do solo e produção vegetal. Tópicos em Ciência do Solo, Viçosa, v.4, p.391-479, 2005.

ABREU JUNIOR, C. H.; NOGUEIRA, T. A. R.; OLIVEIRA, F. C.; PIRES, A. M. M.; FRANCO, A.. Aproveitamento agrícola de resíduos no canavial. In: MARQUES, M. O.; MUTMG, M. A.; NOGUEIRA, T. A. R.; TASSO JÚNIOR, L. C.; NOGUEIRA, G. A.; BERNARDI, J. H.. Tecnologia na agroindústria canavieira. Jaboticabal: FUNEP, 2008, p.183-210.

BITTENCOURT, S.; SERRAT, B. M.; AISSE, M. M.. Gestão do uso agrícola do lodo de esgoto: estudo de caso do estado do Paraná, Brasil. Revista Engenharia Sanitária e Ambiental, Rio de Janeiro, v.22, n.6, p.1129-1139, 2017. DOI: http://doi.org/10.1590/S1413-41522017156260

BRASIL. Lei no 12.305: Institui a Política Nacional de Resíduos Sólidos; altera a Lei № 9.605, de 12 de fevereiro de 1998; e dá outras providências. Brasília: DOU, 2010.

BRASIL. Lei no 9.605: Dispõe sobre as sanções penais e administrativas derivadas de condutas e atividades lesivas ao meio ambiente, e dá outras providências. Brasília: DOU, 1998.

BRASIL. Plano Nacional de Saneamento Básico (versão para apreciação). Brasília: MCIDADES, 2013.

CEPEA. Centro de Estudos Avançados em Economia Aplicada. Informativo CEPEA - Setor Florestal, Piracicaba, n.133-144, p.144, 2013. 
CONAMA. Conselho Nacional de Meio Ambiente. Resolução CONAMA no 374:Define critérios e procedimentos, para uso agrícola de lodos de esgoto gerados em estações de tratamento de esgoto sanitário e seus produtos derivados, e dá outras providências. Brasília: DOU, 2006.

EGAN, M.. Biosolids management strategies: an evaluation of energy prodution as an alternative to land application. Environmental Science and Pollution Research International, Landsberg, v.20, p.4299-4310, 2013.

FARIA, L. C.. Uso do lodo de esgoto (biossólido) como fertilizante em eucaliptos: demanda potencial, produção e crescimento das árvores e viabilidade econômica. Tese (Doutorado em Recursos Florestais) - Universidade de São Paulo, Piracicaba, 2007.

FERNANDES, S. A. P.; BETTIOL, W; CERRI, C. C.. Effect of sewage sludge on microbial biomass, basal respiration, metabolic quotient and soil enzymatic activity. Applied Soil Ecology, Amsterdam, v.30, p.65-77, 2005.

FERRAZ, A. V.; POGGIANI, F.. Biomassa, nutrientes e metais pesados em raízes de eucaliptos adubados com diferentes lodos de esgoto. Cerne, Lavras, v.20, n.2, p.311-320, 2014. DOI: http://dx.doi.org/10.1590/01047760.201420021491

FIRME, L. P.. Produção de madeira e elementos potencialmente tóxicos no sistema solo-eucalipto tratado com lodo de esgoto. Tese (Doutorado em Ciências) - Centro de Energia Nuclear na Agricultura, Universidade de São Paulo, Piracicaba, 2009.

GARCIA, G. O.; GONÇALVES, I. Z.; MADALÃO J. C.; NAZÁRIO, A. A.; REIS, E. F.. Crescimento de mudas de eucalipto submetidas à aplicação de biossólidos. Revista Ciência Agronômica, Fortaleza, v.41, n.1, p.87-94, 2010.

GUEDES, M. C.; ANDRARE, C. A.; POGGIANI, F.; MATTIAZZO, M. E.. Propriedades químicas do solo e nutrição do eucalipto em função da aplicação de lodo de esgoto. Revista Brasileira de Ciência do Solo, Viçosa, v.30, p.267-280, 2006.

HENRY, C. L.; COLE, D. W.. Use of biosolids in the Forest: technology, economics and regulations. Biomass and Bioenergy, Amsterdam, v.13, n.45, p.269-217, 1997.

IEA. Instituto de Economia Agrícola. Levantamento de salários rurais e pagamento de empreita. São Paulo, IEA, 2014.

JUNIO, G.R.Z.; SAMPAIO, R.A.; NASCIMENTO, A.L.; SANTOS, G.B.; SANTOS, L.D.T.; FERNANDES, L.A.. Produtividade de milho adubado com composto de lodo de esgoto e fosfato natural de Gafsa. Revista Brasileira de Engenharia Agrícola e Ambiental, Campina Grande, v.17, n.7, p.706-712, 2013.

LEMAINSKI, J.; SILVA, J. E.. Avaliação agronômica e econômica da aplicação de biossólido na produção de soja. Pesquisa Agropecuária Brasileira, Brasília, v.41, n.10, p.1477-1484, 2006b.

LEMAINSKI, J.; SILVA, J. E.. Utilização do biossólido da CAESB na produção de milho no Distrito Federal. Revista Brasileira de Ciências do Solo, Viçosa, v.30, p.741-750, 2006a.
LIMA JÚNIOR, V. B.; REZENDE, J. L. P.; OLIVEIRA, A. D..

Determinação da taxa de desconto a ser usada na análise econômica de projetos florestais. Revista Cerne, Lavras, v.3, n.1, p.45-66, 1997.

LIMA JÚNIOR, V. B.; REZENDE, J. L. P.; OLIVEIRA, A. D.. Determinação da taxa de desconto a ser usada na análise econômica de projetos florestais. Revista Cerne, Lavras, v.3, n.1, p.45-66, 1997

LIRA, A. C. S.; GUEDES, M. C.; SCHALCH, V.. Reciclagem de lodo de esgoto em plantações de eucalipto: carbono e nitrogênio. Engenharia Sanitária Ambiental, Rio de Janeiro, v.13, n.2, p.207-216, 2008.

LOBO, T. F.; GRASSI FILHO, H.; BULL, L. T.; KUMMER, A. C. B. Efeito do lodo de esgoto e do nitrogênio nos fatores produtivos do girassol. Revista Brasileira de Engenharia Agrícola e Ambiental, Campina Grande, v.15, n.5, p.504-509, 2013.

MACEDO, F. G.; MELO, W. J.; MERLINO, L. C. S.; TORRES, L. S.; GUEDES, A. C. T. P.; MELO, G. M. P.; CAMACHO, M. A.. Lodo de esgoto como fonte de nitrogênio: concentração no perfil do solo e em plantas de milho. Revista Engenharia Sanitária e Ambiental, Rio de Janeiro, v.17, n.13, p.263-268, 2012.

MATSUNGA, M.; BEMELMANS, P. F.; TOLEDO, P. E. N. de; DULLEY, R. D.; OKAWA, H.; PEDROSO, I. A.. Metodologia do custo de produção utilizada pelo IEA.

Agricultura em São Paulo, São Paulo, v.23, n.1, p.123-139, 1976.

PEDROZA, M. M.; VIEIRA, G. E. G.; SOUSA, J. F.; PICKLER, A. C.; LEAL, E. R. M.; MILHOMEN, C. C.. Produção e tratamento de lodo de esgoto - uma revisão. Revista Liberato, Novo Hamburgo, v.11, n.16, p.149-160, 2010.

NORONHA, J. F.. Projetos agropecuários. Piracicaba: FEALQ, 1981.

OSAKI, M.. Gestão financeira e econômica da propriedade rural com multiproduto. Tese (Doutorado em Engenharia de Produção) - Universidade Federal de São Carlos, São Carlos, 2012.

PIRES, A. M. M.; MATTIAZZO, M. E.. Avaliação da viabilidade do uso de resíduo na agricultura. Jaguariúna: Embrapa Meio Ambiente, 2008.

QUINTANA, N. R. G.; BUENO, O. C.; MELO, W. J.. Custo de transporte do lodo de esgoto para viabilidade no uso agrícola. Revista Energia na Agricultura. Revista Científica Eletrônica de Agronomia, Botucatu, v.27, n.3, p.90-96, 2012.

QUINTANA, N. R. G.; CARMO, M. S.; MELO, W. J.. Viabilidade Econômica do uso de lodo de esgoto na agricultura, estado de São Paulo. Informações Econômicas, São Paulo, v.39, n.6, p.31-36, 2009

REZENDE, J. L. P.; OLIVEIRA, A. D.. Análise econômica e social de projetos florestais. Viçosa: Universidade Federal de Viçosa, 2001.

ROCHA, G. N.; GONÇALVES, J. L. M.; MOURA, I. M. Mudanças na fertilidade do solo e crescimento de um 
povoamento de Eucalyptus grandis fertilizado com biossólido. Revista Brasileira de Ciência do Solo, Viçosa, v.28, p.623-639, 2004.

ROCHA, J. H. T.; BACKES, C.; DIOGO, F. A.; PASCOTTO, C. B.; BORELLI, K.. Composto de lodo de esgoto como substrato para mudas de eucalipto. Pesquisa Florestal Brasileira, v.33, n.73, p.27-35, 2013.

SAMPAIO, A. O.. Afinal, queremos ou não viabilizar o uso agrícola do lodo produzido em estações de esgoto sanitário? Uma avaliação crítica da Resolução CONAMA 375. Revista DAE, Curitiba, n.193, p.16-27, 2013. DOI: http://dx.doi.org/10.4322/dae.2014.109

SIFRECA. Sistema de informações de Frete. Boletim SIFRECA Fertilizantes. Piracicaba, Universidade de São Paulo, 2014.

SILVEIRA, R. L. V. A.; GAVA, J. L.. Nutrição e adubação fosfatada em eucalipto. In: TSUIOSHI, Y.; SILVA, R. S. A.. Fósforo na agricultura brasileira. Piracicaba: POTAFOS, 2004. cap.19, p.495-536.
SINGH, R. P.; AGRAWAL, M.. Potential benefits and risks of land application of sewage sludge. Waste Management Amsterdam, v.28, p.347-358, 2007.

SOUZA FILHO, H. M.. Desenvolvimento agrícola sustentável. In: BATALHA, M. O.. Gestão Agroindustrial. São Paulo: Atlas, 2007. p.665-708.

SOUZA, A.; CLEMENTE, A.. Decisões financeiras e análise de investimentos: fundamentos, técnicas e aplicações. 5 ed. São Paulo: Atlas, 2004.

TRANNIN, I. C. B.; SIQUEIRA, J. O.; MOREIRA, F. M. S.. Avaliação agronômica de um biossólido industrial para a cultura de milho. Pesquisa Agropecuária Brasileira, Brasília, v.40, n.3, p.261-269, 2005.

VAZ, L. M. S.; GONÇALVES, J. L. M.. Uso de biossólidos em povoamento de Eucalyptus grandis: efeito em atributos químicos do solo, no crescimento, e na absorção de nutrientes. Revista Brasileira de Ciência do Solo, Viçosa, v.26, p.747-758, 2002.

A CBPC - Companhia Brasileira de Produção Científica (CNPJ: 11.221.422/0001-03) detém os direitos materiais desta publicação. Os direitos referem-se à publicação do trabalho em qualquer parte do mundo, incluindo os direitos às renovaç̃oses, expansões e disseminações da contribuiç̃o, bem como outros direitos subsidiários. Todos os trabalhos publicados eletronicamente poderão posteriormente ser publicados em coletâneas impressas sob coordenação da Sustenere Publishing, da Companhia Brasileira de Produção Científica e seus parceiros autorizados. Os (as) autores (as) preservam os direitos autorais, mas não têm permissão para a publicação da contribuição em outro meio, impresso ou digital, em português ou em tradução. 